OPEN ACCESS

Edited by:

Hatice Hasturk

The Forsyth Institute, United States

Reviewed by:

Tonnie Mulli,

University of Nairobi, Kenya

Loreto Abusleme,

University of Chile, Chile

*Correspondence:

Faleh Tamim

fmarino@qu.edu.qa

Specialty section:

This article was submitted to

Periodontics,

a section of the journal

Frontiers in Dental Medicine

Received: 02 July 2021 Accepted: 02 November 2021 Published: 03 December 2021

Citation:

Cai W, Marouf N, Said KN and Tamimi $F$ (2021) Nature of the Interplay Between Periodontal

Diseases and COVID-19.

Front. Dent. Med. 2:735126.

doi: $10.3389 /$ fdmed.2021.735126

\section{Nature of the Interplay Between Periodontal Diseases and COVID-19}

\author{
Wenji Cai ${ }^{1}$, Nadya Marouf ${ }^{2}$, Khalid N. Said ${ }^{2}$ and Faleh Tamimi ${ }^{3 *}$ \\ ${ }^{1}$ Faculty of Dentistry, McGill University, Montreal, QC, Canada, ${ }^{2}$ Department of Dentistry, Oral Health Institute, Hamad \\ Medical Corporation, Doha, Qatar, ${ }^{3}$ College of Dental Medicine, QU Health, Qatar University, Doha, Qatar
}

The coronavirus disease 2019 (COVID-19) is mostly a mild condition, however, in some patients, it could progress into a severe and even fatal disease. Recent studies have shown that COVID-19 infection and severity could be associated with the presence of periodontitis, one of the most prevalent chronic diseases. This association could be explained by the fact that periodontitis and COVID-19 share some common risk factors that included chronic diseases, such as diabetes and hypertension as well as conditions such as age, sex, and genetic variants. Another possible explanation could be the systemic inflammation and the aspiration of periodontopathogens seen in patients with periodontitis, which could have a synergism with the virus or compromise the reaction of the body against COVID-19. This narrative review explores the nature of these associations, the evidence behind them, and their implications.

Keywords: COVID-19, periodontitis, SARS-CoV-2 (2019-nCoV), cytokine storm, ACE2 (angiotensin converting enzyme-2), co-infection

\section{INTRODUCTION}

The outbreak of the coronavirus disease of 2019 (COVID-19) has been one of the most emergent health problems and public threats in the 21 st century. Despite the fact that the majority of patients present with mild symptoms, more severe cases could lead to pneumonia, sepsis, septic shock, acute respiratory distress syndrome (ARDS), and multi-organ damage or death (1).

The virus responsible for COVID-19, the severe acute respiratory syndrome coronavirus 2 (SARS-CoV-2), infects the upper and lower respiratory system through the respiratory epithelium, and then, it spreads into the bloodstream via endothelial cells causing viremia (2). After the initial viremia, the disease can progress to an acute phase causing systemic inflammation. In some cases, it can deteriorate into life-threatening conditions (10-20\% cases) such as severe pneumonia and/or multi-organ failure, which often require hospitalization and intensive care unit (ICU) admission (3).

The SARS-CoV-2 virus infects host cells using a viral transmembrane spike (S) glycoprotein, called S-protein, that adheres to the human cells by binding to angiotensin converting enzyme II (ACE2), a membrane protein that acts as a receptor for the virus (4). Upon attachment to ACE2, the S-protein is proteolytically cleaved by host proteases, such as TMPRSS2, cathepsin L, or proprotein convertase furin to facilitate viral fusion into the target cells (5-7). Additionally, SARS-CoV-2 can increase the expression of ACE2 further facilitating the infection of host cells (8).

ACE2 is a physiologically functional enzyme with anti-inflammatory properties which are responsible for the conversion of angiotensin II (Ang II) to Ang (1-7) (9). Ang II is a major component in the renin-angiotensin-aldosterone system (RAAS), involved in vasoconstriction, renal sodium reabsorption and potassium excretion, aldosterone 
synthesis, blood pressure elevation, and induction of inflammatory and pro-fibrotic pathways. Ang (1-7) is physiologically active in vasodilatation and opposes the vasoconstriction, counteracting the effects of Ang II (10). By converting Ang II to Ang (1-7), ACE2 plays a role in protecting endothelial function and inhibiting inflammation of endothelial cells, but this role is compromised by SARS-CoV-2 when it binds to ACE2 on the cell membrane (9).

ACE2 is expressed in many organs and tissues but it is most prominent in the respiratory epithelium, endothelium, gastrointestinal system, renal system, and basal epidermal layer of the skin and in the oral and nasal mucosa (11). Hence, a wide range of organs and tissues can be damaged by SARS-CoV-2, resulting in subsequent multiple organ failure observed in the patients with COVID-19. The expression of ACE2 is increased in the patients with certain conditions, such as older age, male sex, and obesity as well as kidney and pulmonary diseases, rendering them more susceptible to the viral invasion and severe COVID-19 cases (8). Interestingly, many of these comorbidities are associated with periodontal diseases.

Periodontal diseases are among the most common diseases that affect adults. It is estimated that about $42 \%$ of those above the age of 30 years old and $60 \%$ of those above the age of 65 years old have periodontitis (12). Severe stages of periodontitis (namely, periodontitis stage 3 and 4) are the sixth most common disease in older adults, affecting about $11 \%$ of the global adult population (13). Periodontitis can have a negative impact on systemic health and has been associated with several risk factors that are also associated with increased risk of COVID-19 complications $(12,14-18)$. Hence, the relationship between periodontitis and COVID-19 disease has drawn great attention from the scientific community. This narrative review summarizes current evidence regarding the pathophysiology and mechanisms underlying the association between periodontal disease and COVID-19.

\section{ASSOCIATION BETWEEN COVID-19 AND PERIODONTITIS}

Several studies give the credence to the association between the COVID-19 and periodontal diseases since the beginning of the pandemic. Three case reports indicated increased gingival bleeding among the patients with COVID-19. This symptom was improved clinically after the viral infection subsided (19). However, these observations were insufficient to show a relationship between periodontitis and COVID-19, especially since it is expected that the patients suffering from COVID-19 may be more likely to neglect oral hygiene when compromised by the symptoms of COVID-19. In fact, a recent publication has reported that the patients with COVID-19 have higher dental plaque scores and gingival edema than their matched SARS-CoV2 negative controls (20).

Larvin et al. analyzed the data on surrogates of periodontitis (e.g., self-reports painful gums, bleeding gums, or loose teeth) from 13,253 participants in the United Kingdom Biobank, that included 1,616 COVID-19 positive cases. Even though they could not link periodontitis with a higher risk of contracting
COVID-19 infection, they observed significantly higher mortality in the patients with COVID-19 with periodontitis (21). However, one weakness of this study was that self-reported oral health indicators may not fully represent periodontitis diagnosis.

In another retrospective study, Sirin and Ozcelik analyzed the dental records and panoramic radiographs of 137 patients with COVID-19 and found a remarkable connection between dental damage and the prognosis of viral disease (22). Also, Marouf et al. conducted a case-control study by collecting the electronic health records, medical as well as dental, of the patients with COVID-19 ( $n=568)$ and analyzed them for the associations between the presence of periodontitis and the severity of COVID19 infections. After adjusting for confounders, such as age, sex, smoking, or comorbidities, a significant association was observed between the presence of periodontitis and COVID19 complications, such as death, ICU admission, or need for assisted ventilation (23). However, one main limitation of this study was that periodontitis was not assessed clinically but it was rather assessed radiographically using interdental bone loss as an indicator of periodontitis.

\section{RISK FACTORS FOR SEVERE PERIODONTITIS AND COVID-19}

Comorbidities and pre-existing conditions associated with severe COVID-19 complications include among others, older age, male sex, African or South Asian race, cardiovascular diseases, cerebrovascular diseases, heart conditions, obesity, smoking, chronic kidney diseases, chronic lung diseases (particularly chronic obstructive pulmonary disease, or COPD), diabetes mellitus with high levels of glycohemoglobin (HbAlc) which marks prolonged increased blood glucose level, hypertension, moderate- to- severe asthma, immunosuppression, cancer, organ transplantation, pregnancy, and elevated blood levels of D-Dimer $(3,24)$. Some of the chronic conditions and diseases increase vulnerability to the virus binding and transmission by favoring ACE2 expression in the affected organs because of tissue damage $(25,26)$. Other conditions, such as moderate- to- severe asthma can compromise the status of the respiratory system, and its vulnerability to excessive inflammation. Moreover, increased $\mathrm{HbA1c}$ levels in patients with diabetes compromise the immune system and impair its phagocytic adherence function. The excessive adipose tissue in obesity is also associated with high expression of ACE2, and insulin resistance, in addition to increased susceptibility to thromboembolisms (27). Pregnancy is related to compromised immunity, and susceptibility to respiratory distress syndrome and hypoxia (28). The higher levels of D-Dimer are associated with an increased risk of coagulability and thrombosis (24).

Periodontitis shares several risk factors mentioned above. These factors are associated with the risk of fast progression of periodontitis (29). Diabetes mellitus and smoking are among the most recognized risk factors for the progression of periodontitis to severe grade, according to the World Workshop on periodontal and peri-implant diseases (29). In addition, obesity is associated with a higher risk of periodontitis progression and 
with the increased levels of proinflammatory cytokines, such as Interleukin- $1 \beta$ (IL-1 $\beta$ ), IL-6, and tumor necrosis factor- $\alpha$ $(\mathrm{TNF}-\alpha)$ in serum and in the gingival crevicular fluid (GCF) of the patients (30-32). This risk is significantly increased in patients who have genetic predisposition to the secretion of IL-1 proinflammatory cytokine (33).

Other mutual risk factors for periodontitis and severe COVID-19 are AIDS, cancer, and Down's syndrome (34). AIDS or HIV infection is associated with acute necrotising gingivitis and periodontitis (35), and severe, rapidly progressing periodontal destruction (36). This pathogenesis is attributed to impaired immune function, challenged by periodontal microorganisms. The patients with cancer undergoing chemotherapy experience a weakening of their immune response, associated with the dysbiosis by altering the ecology of their microbiota. This renders their periodontium more vulnerable to infection and destruction by microbial by-products $(37,38)$. Patients with Down's syndrome have a higher risk of periodontitis due to their compromised oral hygiene, extensive calculus formation, alterations in connective tissues, and capillary morphology, as well as disorders in leukocyte and monocyte function, an important part of the immunological response (39). Periodontitis shares common risk factors with atherosclerosis-associated cardiovascular diseases (12), probably due to the microbial and immunological interactions with atheroma formation $(40,41)$. The patients with active periodontal inflammation are 2.25 times more likely to develop future major cardiovascular events (40).

\section{GENETIC PREDISPOSITION TO COVID-19 AND PERIODONTITIS}

Another possible hypothesis linking periodontitis and severe COVID-19 could be that certain patients might be having genetic variations that could be predisposing them for both diseases. It has been shown that genetic predisposition plays a role in the initiation of severe forms of periodontitis, especially those observed in the younger age groups (42). So far, 65 genes have been associated with higher susceptibility to periodontitis. Many of these genes are known to have various functions in the immune system, and it is thought that their impact on periodontitis may be related to their effect on the inflammatory response to microbial biofilms in the periodontal pocket (42). It could be hypothesized that these same gene expressions concur with other chronic inflammatory diseases, such as coronary artery disease, diabetes, metabolic syndrome, obesity, and other inflammatory mediated diseases (12). For this reason, it could also be hypothesized that this genetic makeup could also be linked to the susceptibility of some individuals to severe COVID-19.

Indeed, several genes have been associated with severe COVID-19 outcomes. These include, so far, the following: ACE2, TMPRSS2, CD26(DPP4), IFITM3, HLA, ABO, SLC6A20, GSTT1-M1, DBP, and IL6 $(43,44)$. Interestingly, some of these genes are known to play a role in periodontitis. For example, CD26 or namely dipeptidyl peptidase IV (DPP4) was also found to be expressed in fibroblastic cells of human periodontal tissues when exposed to periodontal pathogens (45). Human leukocyte antigens (HLA) play a vital role in antigen recognition and communication of periodontopathogens, whereas HLA$\mathrm{A}^{*} 02 / \mathrm{B}^{*} 40$ haplotype was found contributing to the development of chronic periodontitis among the Brazilians (46). GSTM1null genotype was found to be linked to chronic periodontitis and its combination with GSTT1- null genotype could lead to aggressive periodontitis (47). Additionally, IL-6-174C allele has been associated with an increased risk of gingivitis in Caucasian children (48).

Thus, it could be hypothesized that in some patients the association between severe COVID-19 and periodontitis could in part be driven by genetic phenotypes involving CD26, HLA, and GSTT1-M1. In addition, in the presence of predisposing genes, environmental factors, such as obesity, smoking, and stress could induce the expression of the genes against the microbial challenge in the periodontal pocket thus inducing severe inflammatory response leading to tissue destruction (42).

It is worth noting that the association between periodontitis and COVID-19 complications seems to be stronger among the younger patients (23). Given the fact that the onset of periodontitis at a younger age has a strong genetic component, it could be speculated that the presence of periodontitis in young patients could be a sign of a genetic variation that favors COVID19 complications, although future genetic research would be needed to confirm this.

\section{ACE2, TMPRSS2, AND PERIODONTITIS}

Some reports have proposed that the oral mucosa could play an important role in the entry of the virus into the body, especially in the patients with periodontitis (49). Membrane proteins and enzymes used by SARS-CoV-2 to infect cells can be found in abundance in the oral cavity $(50,51)$, ACE2 is highly enriched in epithelial cells of the oral mucosa (52) and in salivary glands (53), and TMPRSS members are broadly enriched in epithelial cells of the salivary glands, oral mucosa, and gingiva tissues (54). In addition, the expression of these membrane proteins and enzymes is influenced by the presence of periodontitis. Cathepsin L and CD147 can be elevated in the GCF of patients with chronic periodontitis (55-58). Furthermore, the bioinformatic analyses have shown that periodontitis could induce an increase in microRNA-146 and-155 in the oral cavity, which is predicted to upregulate the expression of ACE2 (59). Moreover, in vitro studies have confirmed this prediction by showing an upregulation of ACE2 in alveolar epithelial cells when exposed to the periodontopathic bacteria Fusibactereum nucleatum (F. nucleatum).

\section{PERIODONTAL BACTERIA IN THE LUNGS}

Co-infections and/or secondary infections by bacteria, such as ventilator-associated pneumonia in the patients with COVID-19 (60), could augment the pathogenesis, thus escalating morbidity or mortality during viral invasion. Periodontopathogens and other oral bacteria could play a role in such infections since they 
have been found in the lower respiratory tract of the patients with pneumonia and have long been associated with respiratory conditions that could synergize with the viral infections to cause adverse outcomes (61). More specifically, periodontopathic bacteria, such as $F$. nucleatum and Prevotella intermedia ( $P$. intermedia), have been found in the bronchoalveolar lavage fluid (BALF) of the patients with bacterial pneumonia $(61,62)$. Supernatant of $F$. nucleatum has been found to upregulate ACE2 in the alveolar epithelial cells in vitro (63), while $P$. intermedia enhanced the expression of platelet-activating factor receptor used by pneumonia-causing bacteria to infect the lungs (64). In addition, F. nucleatum was found to induce IL6 and IL-8 production in alveolar, bronchial, and pharyngeal epithelial cells, supporting the hypothesis that aspiration of periodontopathic contaminated saliva into the lower respiratory tract might aggravate COVID-19 infection (63). These effects of periodontopathogens on alveolar cells could suggest that their aspiration into the lungs and bronchus might increase the vulnerability of patients to COVID-19 infection (63).

\section{SARS-COV-2 IN PERIODONTAL POCKETS}

Periodontal pockets can serve as potential viral reservoirs. Herpes simplex virus (HSV), active human cytomegalovirus (HCMV), and other viral species have been isolated from pockets of severe periodontitis (Stage 3 and 4 ) patients $(65,66)$, and severe periodontitis has been associated with reactivated herpes viruses (65). Interestingly, Gupta et al. found coronavirus accumulated in GCF in the asymptomatic and mildly symptomatic patients with COVID-19 (67). Thus, Badran et al. hypothesized that periodontal pockets might also play as a reservoir of SARS-CoV-2 and increase the viral load in the infected individual (68).

\section{MICROBIOME DYSBIOSIS IN PERIODONTITIS AND COVID-19}

The oral cavity represents the second largest microbial community in the human body after the gut, dominated by bacteria in homeostasis (69). But it can shift to dysbiosis when there are increased numbers of pathogens at the loss of beneficial commensal bacteria and microbial diversity (70). Periodontitis is primarily an inflammatory disease initiated by oral microbial plaque organized in the form of a complex microbial biofilm (71). The complex microbial infection induces a cascade of immune reactions starting from an acute inflammatory response that could progress into a prolonged, self-destructive immune reaction that destroys the periodontal attachment apparatus, such as the alveolar bone and periodontal ligament fibers attaching the teeth to the jaws.

Bacteria play an essential role in the initiation and progression of periodontitis. Indeed, the experiments done in sterile conditions have shown that periodontal tissue destruction does not occur in the absence of putative periodontal pathogens (72), and management of the microbial infection is the most predictable treatment of periodontitis (73). In clinically healthy gingiva, the gingival crevice is populated by large amounts of bacteria comprising normal flora. However, microbial dysbiosis of these bacteria toward certain pathological species provokes inflammation in the periodontal tissues manifested clinically as gingivitis and periodontitis $(65,73-75)$. Some of the most common pathogens associated with these conditions include among others $P$. intermedia, Porphyromonsa gingivalis ( $P$. gingivalis), $F$. nucleatum, Treponema denticola (T. denticola), or Aggregatibacter actinomycemetcomitans (A. actinomycemetcomitans). In addition, oral dysbiosis is linked to several systemic diseases, such as atherosclerosis, Alzheimer's disease, or head and neck cancer (76). Oral dysbiosis could favor viral infections since viruses exploit bacteria co-inhabitants to enhance their entry into the host cells $(77,78)$. This is why viralbacterial co-infection has been proposed as a possible mechanism for pathogenesis in certain types of periodontitis (79). Moreover, the presence of oral microbes in other organs distant from the oral cavity had shed light on the importance of the oral microbiome in general health and the potential of emerging treatment modalities targeting oral dysbiosis (76).

Interestingly, the patients with COVID-19 have been found to present periodontopathogens and oral dysbiosis that correlates to the severity of the disease (80). Although it is not possible to determine whether the alteration in the oral microbial community is the cause or effect of the SARS-CoV-2 replication or pathogenesis, these parameters may be considered as markers for personalized therapy and vaccine development.

\section{IMMUNOPATHOGENESIS OF PERIODONTITIS AND COVID-19}

A possible link between periodontitis and COVID-19 severity could be through the immune system and the inflammatory response to these diseases. It has been hypothesized that the synergy between severe COVID-19 and periodontal disease might be the result of their immune stimulation.

Bacterial and viral invasions should be confronted by a selflimited inflammatory response that is followed by a complete resolution. However, the pathogenicity and virulence of such infections might result in an inflammation that is not selfcontrolled, while this excessive immune response can lead to adverse outcomes. In many diseases, such as periodontitis, this means the loss of soft and hard tissues, while in COVID-19, it involves cytokine storm, ARDS, and multi-organ failure.

The inflammatory markers associated with severe COVID-19, such as C-reactive protein (CRP), D-Dimer, and increased white blood cell (WBC) count were found to be significantly elevated in the patients with COVID-19 who have stages 2, 3, and 4 of periodontitis compared with those who do not have periodontitis (23). Respiratory diseases, such as bronchial asthma (81), COPD, and pneumonia (82) are linked to periodontitis and share similar proinflammatory cytokines (83).

The "cytokine storm," a vicious cycle of stimulation and excessive production of proinflammatory cytokines and mediators induced by severe SARS-CoV-2 infection, appears to be a major cause of disease severity, multiple-organ failure, and death in the patients with COVID-19 (84). Thus, understanding 
the underlying mechanisms behind it is crucial for fighting the disease, and reducing its mortality (85). Cytokine storm is characterized by the increased serum levels of liver enzymes, creatinine, and interleukins IL-2, IL-6, IL-7, IL-10, and IL-17 (86); IP-10 (an inflammatory chemokine induced by interferon IFN- $\gamma$ and usually found increased in severe acute respiratory infections) (87), monocyte chemoattractant protein-1 (MCP1); tumor necrosis factor- $\alpha$ (TNF- $\alpha$ ); granulocyte-colony stimulating factor (GCS); monocyte chemotactic and neutrophils as well as a decrease in lymphocyte counts $\left(\mathrm{CD}^{+}\right.$cells and $\mathrm{CD}^{+}$cells). The exaggerated immune reaction shifts the immunological function toward harm rather than repair, causing the excessive pulmonary infiltrate, viewed on the chest radiographic images as bilateral infiltration without cardiac involvement (88).

The cytokine storm observed in the severe cases of COVID-19 is linked to impairments in the acquired and innate inflammatory responses, and this is often associated with chronic diseases affecting the immune system (88), or predisposing genetic conditions $(89,90)$.

Periodontitis initiates complex cascades of innate/adaptive cellular and humoral immune reactions, leading to persistent inflammatory status associated with the release of proinflammatory cytokines (i.e., TNF- $\alpha$, IL- $1 \beta$, and IL-6) into the periodontal tissues and the bloodstream $(65,91-94)$. Many of these cytokines are also known to play a crucial role in COVID-19. For example, the expression of IL-6 is known to be a strong predictor of critical illness and mortality among the patients with COVID-19 $(95,96)$. IL-6 inflammatory response via gingival fibroblasts can lead to increased Cathepsin L expression which favors coronavirus adhesion (97). Moreover, aspiration of periodontopathogens, such as F. nucleatum could induce IL-6 production by alveolar epithelial cells as well as bronchial and pharyngeal epithelial cells (63), which in turn could promote SARS-CoV-2 infection and worsen the severity of viral pneumonia (98).

Another manifestation of the cytokine storm observed in COVID-19 as well as in certain other viral infections, such as MERS-CoV, SARS-CoV, and nvH1N1 influenza is elevated Th17 inflammatory responses and IL-17 production (86, 99101). Interestingly, the patients with periodontitis also present increased levels of IL-17 producing cells in the periodontal tissues $(102,103)$ as well as the high levels of IL-17 in serum (104). IL-17 has a significant role in periodontal bone resorption and destruction due to its impact on chemokines secretions of osteoblasts (105). Therefore, it has been suggested that the severe COVID-19 cytokine storm and periodontitis might be associated with the Th17 immune pathway (106).

In addition, periodontitis is characterized by a dysregulated neutrophil response to specific bacterial species. This involves the overproduction and impaired removal of neutrophil extracellular traps (NETs), an alternative form of cell death (107). Many viruses can also stimulate neutrophils to produce NETs (108). Of note, NETs increase in the patients with ARDS (109), and in those with COPD during the acute respiratory failure phase (110). NETs generation has also been involved in venous and arterial thrombosis $(111,112)$, another life-threatening complication that has been observed in SARS-CoV-2 infection $(14,113)$. Since NETs upregulation is observed in the patients with both COVID-19 and periodontitis, it has been hypothesized that periodontitis could be predisposing the patients with COVID-19 to develop severe forms of the disease through the production of NETS. However, there is still no direct evidence available linking NETs generation in periodontitis and the severity of COVID-19 disease, hence NETs-oriented studies are suggested in the future.

Another proposed immunological link between periodontitis and COVID-19 is through Galectin 3 (Gal-3), a proinflammatory protein and has been involved in the disease process of various inflammatory conditions (114). Gal-3 has a morphology that is almost identical to the spike protein of SARS-CoV2 which is critical for the virus entry into the host cells (115). Gal-3 inhibition could also decrease IL-6 production (116), suggesting it could be a potential therapeutic target in patients with COVID-19. Moreover, human saliva contains exosome-like vesicles with Gal-3 which might regulate the local immune defense in the oral cavity by enhancing phagocytic activity of neutrophils and stimulation of cytokines production (117). However, even though Gal-3 affects the key processes involved in periodontitis, so far there is no clinical evidence demonstrating its possible role in the development of the disease.

Specialized pro-resolving mediators (SPMs) are endogenous lipid mediators that are biosynthesized during the acute inflammatory response which help in all resolution phases of the inflammation (118) and are pivotal to returning the affected tissues to healthy working order (119). Multiple animal studies indicate that exogenous administration of SPMs could dramatically help in healing the periapical lesions and reducing inflammation in periodontitis (120-122), and hence they could also help manage the COVID-19 complications. However, clinical studies are still needed to optimize the applications of SPMs in treating periodontal diseases.

\section{MANAGEMENT FOR PERIODONTITIS AND COVID-19}

Numerous papers have shown that periodontal treatments improve the levels of serum markers of systemic inflammation (123) as well as systemic medical conditions, such as COPD and diabetes (124). For example, Katagiri et al. suggested periodontal treatment with topical antibiotics could improve the levels of HbA1c through reduction of CRP and ameliorated insulin resistance in type 2 diabetes (125); Shimada et al. demonstrated that scaling and root planing (SRP), a mechanical periodontal therapy, could reduce IL-6, CRP, and leptin in the serum of the patients with periodontitis (126). Terry et al. also concluded that SRP could improve glycemic control in people with diabetes and reduce HbAlc serum level (127). Abe et al. indicated that weekly professional oral care is effective to prevent influenza infection in the older patients by reducing oral bacterial and viral activities (128); Chambrone et al. suggested positive effects of periodontal treatment on diabetesassociated renal function (129). Teeuw et al. demonstrated 
through a meta-analysis that the periodontal treatments improve endothelial function and reduce the atherosclerotic biomarkers (130). However, the interventional clinical studies are still needed to draw a definitive conclusion on the ability of periodontal treatments to prevent atherosclerotic cardiovascular disease (131). Nonetheless, we still suggest a potential effect of periodontal treatment on COVID-19 disease control.

\section{DISCUSSION}

In summary, COVID-19 complications, such as ARDS and multiorgan failure, are mainly caused by severe systemic inflammation and thrombotic lesions (132). These complications are associated with certain risk factors and conditions, many of which are also linked to periodontitis. These possible associations between periodontitis and COVID-19 complications could stem from either a direct effect of periodontitis on systemic inflammation, from an indirect effect of periodontitis on other risk factors of COVID-19, or due to predisposing conditions common

\section{REFERENCES}

1. Yang X, Yu Y, Xu J, Shu H, Xia Ja, Liu H, et al. Clinical course and outcomes of critically ill patients with SARS-CoV-2 pneumonia in Wuhan, China: a single-centered, retrospective, observational study. Lancet Respir Med. (2020) 8:475-81. doi: 10.1016/S2213-2600(20)30079-5

2. de la Rica $R$, Borges $M$, Gonzalez-Freire M. COVID-19: in the eye of the cytokine storm. Front Immunol. (2020) 11:558898. doi: 10.3389/fimmu.2020.558898

3. Gao YD, Ding M, Dong X, Zhang JJ, Kursat Azkur A, Azkur D, et al. Risk factors for severe and critically ill COVID-19 patients: a review. Allergy. (2021) 76:428-55. doi: 10.1111/all.14657

4. Walls AC, Park YJ, Tortorici MA, Wall A, McGuire AT, Veesler D. Structure, function, and antigenicity of the SARS-CoV-2 spike glycoprotein. Cell. (2020) 181:281-92 e6. doi: 10.1016/j.cell.2020.02.058

5. Shang JA-O, Wan Y, Luo C, Ye G, Geng Q, Auerbach AA-O, et al. Cell Entry Mechanisms of SARS-CoV-2. Proc Natl Acad Sci U S A. 117:1172734. doi: 10.1073/pnas.2003138117

6. Hoffmann M, Kleine-Weber H, Schroeder S, Krüger N, Herrler T, Erichsen S, et al. SARS-CoV-2 cell entry depends on ACE2 and TMPRSS2 and is blocked by a clinically proven protease inhibitor. Cell. 181:27180.e8. doi: 10.1016/J.CELL.2020.02.052

7. Ou X, Liu Y, Lei X, Li P, Mi D, Ren L, et al. Characterization of spike glycoprotein of SARS-CoV-2 on virus entry and its immune cross-reactivity with SARS-CoV. Nat Commun. 11:1620. doi: 10.1038/s41467-020-15562-9

8. Phan LT, Nguyen TV, Luong QC, Nguyen TV, Nguyen HT, Le HQ, et al. Importation and human-to-human transmission of a novel coronavirus in Vietnam. N Engl J Med. (2020) 382:872-4. doi: 10.1056/NEJMc2001272

9. Issa $\mathrm{H}$, Eid $\mathrm{AH}$, Berry $\mathrm{B}$, Takhviji V, Khosravi A, Mantash S, et al. Combination of angiotensin (1-7) agonists and convalescent plasma as a new strategy to overcome angiotensin converting enzyme 2 (ACE2) inhibition for the treatment of COVID-19. Front Med. (2021) 8:620990. doi: 10.3389/fmed.2021.620990

10. Heyman SN, Walther TA-O, Abassi Z. Angiotensin-(1-7)-a potential remedy for AKI: insights derived from the COVID-19 pandemic. J Clin Med. (2021) 10:1200. doi: $10.3390 / \mathrm{jcm} 10061200$

11. Bourgonje AR, Abdulle AE, Timens W, Hillebrands JL, Navis GJ, Gordijn SJ, et al. Angiotensin-converting enzyme 2 (ACE2), SARS-CoV-2 and the pathophysiology of coronavirus disease (2019) (COVID-19). J Pathol. (2020) 251:228-48. doi: 10.1002/path.5471 to both periodontitis and COVID-19, such as diabetes and genetic variants.

The association between COVID-19 and periodontitis does not imply causality, but it does raise a call for further research to deepen our understanding of the nature and mechanisms underlying it. This might be insightful in the terms of early prevention and management of complications in the patients with COVID-19 and may help in clinical decision making.

\section{AUTHOR CONTRIBUTIONS}

FT, WC, NM, and KS contributed to the ideas, the manuscript, and the revision. All authors contributed to the article and approved the submitted version.

\section{ACKNOWLEDGMENTS}

We thank librarian Martins Morris from the Faculty of Dentistry at McGill University, Canada, for his help in searching related literature.

12. Genco RJ, Sanz M. Clinical and public health implications of periodontal and systemic diseases: an overview. Periodontol. (2020) 83:7-13. doi: 10.1111/prd.12344

13. Global, regional, and national incidence, prevalence, and years lived with disability for 301 acute and chronic diseases and injuries in 188 countries, 1990-2013: a systematic analysis for the global burden of disease study (2013). Lancet. (2015) 386:743-800.

14. Zhou F, Yu T, Du R, Fan G, Liu Y, Liu Z, et al. Clinical course and risk factors for mortality of adult inpatients with COVID-19 in Wuhan, China: a retrospective cohort study. Lancet. (2020) 395:105462. doi: 10.1016/S0140-6736(20)30566-3

15. Wu C, Chen X, Cai Y, Xia J, Zhou X, Xu S, et al. Risk factors associated with acute respiratory distress syndrome and death in patients with coronavirus disease (2019). Pneumonia in Wuhan, China. JAMA Intern Med. (2020) 180:934-43. doi: 10.1001/jamainternmed.2020.0994

16. Sanz M, Ceriello A, Buysschaert M, Chapple I, Demmer RT, Graziani F, et al. Scientific evidence on the links between periodontal diseases and diabetes: consensus report and guidelines of the joint workshop on periodontal diseases and diabetes by the international diabetes federation and the european federation of periodontology. J Clin Periodontol. (2018) 45:138-49. doi: 10.1111/jcpe.12808

17. Romandini M, Baima G, Antonoglou G, Bueno J, Figuero E, M S. Periodontitis, edentulism, and risk of mortality: a systematic review with meta-analyses. $J$ Dent Res. 2020:22034520952401. doi: 10.1177/0022034520952401

18. Sanz M, Marco Del Castillo A, Jepsen S, Gonzalez-Juanatey JR, D’Aiuto F, Bouchard P, et al. Periodontitis and cardiovascular diseases: consensus report. J Clin Periodontol. (2020) 47:268-88. doi: 10.1111/jcpe.13189

19. Manzalawi R, Alhmamey K, Abdelrasoul M. Gingival bleeding associated with COVID-19 infection. Clinical Case Reports. (2021) 9:294-7. doi: $10.1002 / \mathrm{ccr} 3.3519$

20. Anand PS, Jadhav P, Kamath KP, Kumar SR, Vijayalaxmi S, Anil S. A casecontrol study on the association between periodontitis and coronavirus disease (COVID-19). J Periodontol. (2021) doi: 10.1002/JPER.21-0272

21. Larvin H, Wilmott S, Wu J, Kang J. The impact of periodontal disease on hospital admission and mortality during COVID-19 pandemic. Front Med. (2020) 7:604980. doi: 10.3389/fmed.2020.604980

22. Sirin DA, Ozcelik F. The relationship between COVID-19 and the dental damage stage determined by radiological examination. Oral Radiology. (2021) 03:03 doi: 10.1007/s11282-020-00497-0 
23. Marouf N, Cai W, Said KN, Daas H, Diab H, Chinta VR, et al. Association between periodontitis and severity of COVID-19 infection: a case-control study. J Clin Periodontol. (2021) 48:483-91. doi: 10.1111/jcpe.13435

24. Dessie ZG, Zewotir T. Mortality-related risk factors of COVID-19: a systematic review and meta-analysis of 42 studies and 423,117 patients. BMC Infect Dis. (2021) 21:855. doi: 10.1186/s12879-021-06536-3

25. Sama IE, Ravera A, Santema BT, van Goor H, Ter Maaten JM, Cleland JGF, et al. Circulating plasma concentrations of angiotensinconverting enzyme 2 in men and women with heart failure and effects of renin-angiotensin-aldosterone inhibitors. Eur Heart J. (2020) 41:18107. doi: 10.1093/eurheartj/ehaa373

26. Kornilov SA, Lucas I, Jade K, Dai CL, Lovejoy JC, Magis AT. Plasma levels of soluble ACE2are associated with sex, metabolic syndrome, and its biomarkers in a large cohort, pointing to a possible mechanism for increased severity in COVID-19. Crit Care. (2020) 24:452. doi: 10.1186/s13054-020-03141-9

27. Al-Benna S. Association of high level gene expression of ACE2 in adipose tissue with mortality of COVID-19 Infection in obese patients. Obes Med. (2020) 19:100283. doi: 10.1016/j.obmed.2020.100283

28. Wastnedge EAN, Reynolds RM, van Boeckel SR, Stock SJ, Denison FC, Maybin JA, et al. Pregnancy and COVID-19. Physiological Reviews. (2021) 101:303-18. doi: 10.1152/physrev.00024.2020

29. Papapanou PN, Sanz M, Buduneli N, Dietrich T, Feres M, Fine $\mathrm{DH}$, et al. Periodontitis: consensus report of workgroup 2 of the (2017). World workshop on the classification of periodontal and periimplant diseases and conditions. J Periodontol. (2018) 89 Suppl 1:S173S82. doi: 10.1002/JPER.17-0721

30. Moschen AR, Molnar C, Enrich B, Geiger S, Ebenbichler CF, Tilg H. Adipose and liver expression of interleukin (IL)-1 family members in morbid obesity and effects of weight loss. Mol Med. (2011) 17:8405. doi: 10.2119/molmed.2010.00108

31. Satpathy A, Ravindra S, Thakur S, Kulkarni S, Porwal A, Panda S. Serum interleukin-1 $\beta$ in subjects with abdominal obesity and periodontitis. Obes Res Clin Pract. (2015) 9:513-21. doi: 10.1016/j.orcp.2015.01.005

32. Choi J, Joseph L, Pilote L. Obesity and C-Reactive protein in various populations: a systematic review and meta-analysis. Obes Rev. (2013) 14:23244. doi: $10.1111 /$ obr.12003

33. Wilkins LM, Kaye EK, Wang HY, Rogus J, Doucette-Stamm L, Kornman $\mathrm{K}$, et al. Influence of obesity on periodontitis progression is conditional on interleukin-1 inflammatory genetic variation. J Periodontol. (2017) 88:5968. doi: 10.1902/jop.2016.160408

34. Rosenthal N, Cao Z, Gundrum J, Sianis J, Safo S. Risk factors associated with in-hospital mortality in a US national sample of patients with COVID-19. JAMA Netw Open. (2020) 3:E2029058. doi: 10.1001/jamanetworkopen.2020.29058

35. Winkler JR, Robertson PB. Periodontal disease associated with HIV Infection. Oral Surg Oral Med Oral Pathol. (1992) 73:145-50. doi: 10.1016/0030-4220(92)90186-T

36. Riley C, London JP, Burmeister JA. Periodontal health in 200 HIV-positive patients. J Oral Pathol Med. (1992) 21:1247. doi: 10.1111/j.1600-0714.1992.tb00995.x

37. Francescangeli F, De Angelis ML, Baiocchi M, Rossi R, Biffoni M, Zeuner A. COVID-19-induced modifications in the tumor microenvironment: do they affect cancer reawakening and metastatic relapse? Front Oncol. (2020) 10:592891. doi: 10.3389/fonc.2020.592891

38. Williamson EJ, Walker AJ, Bhaskaran K, Bacon S, Bates C, Morton CE, et al. Factors associated with COVID-19-related death using OpenSAFELY. Nature. (2020) 584:430-6. doi: 10.1038/s41586-020-2521-4

39. Reuland-Bosma W, van Dijk J. Periodontal disease in down's syndrome: a review. J Clin Periodontol. (1986) 13:6473. doi: 10.1111/j.1600-051X.1986.tb01416.x

40. Van Dyke TE, Kholy KE, Ishai A, Takx RAP, Mezue K, Abohashem $\mathrm{SM}$, et al. Inflammation of the periodontium associates with risk of future cardiovascular events. J Periodontol. (2021) 92:348-58. doi: 10.1002/JPER.19-0441

41. Schenkein HA, Papapanou PN, Genco R, Sanz M. Mechanisms underlying the association between periodontitis and atherosclerotic disease. Periodontol. (2020). 83:90-106. doi: 10.1111/prd.12304
42. Loos BG, Van Dyke TE. The role of inflammation and genetics in periodontal disease. Periodontol. (2020). 83:26-39. doi: 10.1111/prd.12297

43. Kaltoum ABO. Mutations and polymorphisms in genes involved in the infections by covid 19: a review. Gene Rep. (2021) 23:101062. doi: 10.1016/j.genrep.2021.101062

44. Senapati S, Kumar S, Singh AK, Banerjee P, Bhagavatula S. Assessment of risk conferred by coding and regulatory variations of TMPRSS2 and CD26 in susceptibility to SARS-CoV-2 infection in human. J Genet. (2020) 99:53. doi: 10.1007/s12041-020-01217-7

45. Nemoto E, Sugawara S, Takada H, Shoji S, Horiuch H. Increase of CD26/dipeptidyl peptidase IV expression on human gingival fibroblasts upon stimulation with cytokines and bacterial components. Infect Immun. (1999) 67:6225-33. doi: 10.1128/IAI.67.12.6225-6233.1999

46. Sippert E, de Oliveira e Silva C, Ayo CM, Marques SB, Visentainer JE, Sell AM. HLA haplotypes and genotypes frequencies in Brazilian chronic periodontitis patients. Mediators Inflamm. (2015) 2015:481656. doi: 10.1155/2015/481656

47. Concolino P, Cecchetti F, D'Autilia C, Santonocito C, Di Stasio E, Zuppi C, et al. Association of periodontitis with GSTM1/GSTT1-null variants-a pilot study. Clin Biochem. (2007) 40:939-45. doi: 10.1016/j.clinbiochem.2007.04.012

48. Holla LI, Musilova K, Vokurka J, Klapusová L, Pantuckova P, Kukletova $\mathrm{M}$, et al. Association of interleukin-6 (IL-6) haplotypes with plaqueinduced gingivitis in children. Acta Odontol Scand. (2008) 66:10512. doi: 10.1080/00016350802004664

49. Graham Lloyd-Jones SM, Carla Cruvinel Pontes, Iain L C Chapple. The COVID-19 pathway: a proposed oral-vascular-pulmonary route of SARSCoV-2 infection and the importance of oral healthcare measures. J Oral Med Oral Surg. (2021). 2:S1.

50. Pascolo L, Zupin LA-O, Melato M, Tricarico PM, Crovella S. TMPRSS2 and ACE2 coexpression in SARS-CoV-2 salivary glands infection. J Dent Res. 99:1120-1. doi: 10.1177/0022034520933589

51. Sakaguchi W, Kubota N, Shimizu T, Saruta JA-O, Fuchida S, Kawata A, et al. Existence of SARS-CoV-2 entry molecules in the oral cavity. Int J Mol Sci. 21:6000. doi: 10.3390/ijms21176000

52. Xu H, Zhong L, Deng J, Peng J, Dan H, Zeng X, et al. High expression of ACE2 receptor of 2019-NCoV on the epithelial cells of oral mucosa. Int J Oral Sci. (2020) 12:8. doi: 10.1038/s41368-020-0074-x

53. Descamps G, Verset L, Trelcat A, Hopkins C, Lechien JR, Journe F, et al. ACE2 protein landscape in the head and neck region: the conundrum of SARS-CoV-2 infection. Biology. (2020) 9:235. doi: 10.3390/biology9080235

54. Huang N, Pérez P, Kato T, Mikami Y, Okuda K, Gilmore RC, et al. SARSCoV-2 infection of the oral cavity and saliva. Nat Med. (2021) 27:892903. doi: 10.1038/s41591-021-01296-8

55. Macabeo-Ong M, Shiboski CH, Silverman S, Ginzinger DG, Dekker N, Wong DTW, et al. Quantitative analysis of cathepsin L MRNA and protein expression during oral cancer progression. Oral Oncology. (2003) 39:63847. doi: 10.1016/S1368-8375(03)00034-4

56. Ryder MI, Hyun W, Loomer P, Haqq C. Alteration of gene expression profiles of peripheral mononuclear blood cells by tobacco smoke: implications for periodontal diseases. Oral Microbiol Immunol. 19:3949. doi: 10.1046/j.0902-0055.2003.00110.x

57. Wang K, Chen W, Zhang Z, Deng Y, Lian JQ, Du P, et al. CD147-spike protein is a novel route for SARS-CoV-2 infection to host cells. Signal Transduct Target Ther. 5:283. doi: 10.1038/s41392-020-00426-X

58. Feldman M, La VD, Lombardo Bedran TB, Palomari Spolidorio DM, Grenier D. Porphyromonas gingivalis-mediated shedding of extracellular matrix metalloproteinase inducer (EMMPRIN) by oral epithelial cells: a potential role in inflammatory periodontal disease. Microbes Infect. 13:1261-9. doi: 10.1016/j.micinf.2011.0 7.009

59. Roganovic JR. MicroRNA-146a and-155, upregulated by periodontitis and type 2 diabetes in oral fluids, are predicted to regulate SARS-CoV-2 oral receptors genes. J Periodontol. (2020) 18:18. doi: 10.1002/JPER.20-0623

60. Ippolito MA-O, Misseri G, Catalisano GA-O, Marino C, Ingoglia $\mathrm{G}$, Alessi $\mathrm{M}$, et al. Ventilator-associated pneumonia in patients with COVID-19: a systematic review and meta-analysis. Antibiotics. (2021) 10:545. doi: 10.3390/antibiotics 10050545 
61. Yamasaki K, Kawanami T, Yatera K, Fukuda K, Noguchi S, Nagata S, et al. Significance of anaerobes and oral bacteria in community-acquired pneumonia. PLoS ONE. (2013) 8:E63103. doi: 10.1371/journal.pone.0063103

62. Nagaoka K, Yanagihara K, Harada Y, Yamada K, Migiyama Y, Morinaga $\mathrm{Y}$, et al. Quantitative detection of periodontopathic bacteria in lower respiratory tract specimens by real-time PCR. J Infect Chemother. (2017) 23:69-73. doi: 10.1016/j.jiac.2016.09.013

63. Takahashi Y, Watanabe N, Kamio N, Yokoe S, Suzuki R, Sato S, et al. Expression of the SARS-CoV-2 receptor ace2 and proinflammatory cytokines induced by the periodontopathic bacterium fusobacterium nucleatum in human respiratory epithelial cells. Int. (2021) 22:29. doi: 10.3390/ijms22031352

64. Nagaoka K, Yanagihara K, Morinaga Y, Nakamura S, Harada T, Hasegawa $\mathrm{H}$, et al. Prevotella intermedia induces severe bacteremic pneumococcal pneumonia in mice with upregulated platelet-activating factor receptor expression. Infect Immun. (2014) 82:587-93. doi: 10.1128/IAI.00943-13

65. Slots J. Periodontitis: facts, fallacies and the future. Periodontol 2000. (2017). 75:7-23. doi: 10.1111/prd.12221

66. Cappuyns I, Gugerli P, Mombelli A. Viruses in periodontal disease - a review. Oral Dis. (2005) 11:219-29. doi: 10.1111/j.1601-0825.2005.01123.x

67. Gupta SA-O, Mohindra R, Chauhan PK, Singla V, Goyal K, Sahni V, et al. SARS-CoV-2 detection in gingival crevicular fluid. J dent Res. (2021) 100:187-93. doi: 10.1177/0022034520970536

68. Badran Z, Gaudin A, Struillou X, Amador G, Soueidan A. Periodontal pockets: a potential reservoir for SARS-CoV-2? Med Hypotheses. (2020) 143:109907. doi: 10.1016/j.mehy.2020.109907

69. Deo PN, Deshmukh R. Oral microbiome: unveiling the fundamentals. J Oral Maxillofac Pathol. (2019) 23:122-8. doi: 10.4103/jomfp.JOMFP_152_19

70. Petersen C, Round JL. Defining dysbiosis and its influence on host immunity and disease. Cell Microbiol. (2014) 16:1024-33. doi: 10.1111/cmi.12308

71. Kononen E, Gursoy M, Gursoy UK. Periodontitis: a multifaceted disease of tooth-supporting tissues. J Clin Med. (2019) 8:1135. doi: $10.3390 / \mathrm{jcm} 8081135$

72. Hajishengallis G, Liang S, Payne MA, Hashim A, Jotwani R, Eskan MA, et al. Low-abundance biofilm species orchestrates inflammatory periodontal disease through the commensal microbiota and complement. Cell Host Microbe. (2011) 10:497-506. doi: 10.1016/j.chom.2011.10.006

73. Curtis MA, Diaz PI, Van Dyke TE. The role of the microbiota in periodontal disease. Periodontol. (2020). 83:14-25. doi: 10.1111/prd.12296

74. Abusleme L, Dupuy AK, Dutzan N, Silva N, Burleson JA, Strausbaugh LD, ET AL. The subgingival microbiome in health and periodontitis and its relationship with community biomass and inflammation. ISME J. (2013) 7:1016-25. doi: 10.1038/ismej.2012.174

75. Hong BY, Furtado Araujo MV, Strausbaugh LD, Terzi E, Ioannidou E, Diaz PI. Microbiome profiles in periodontitis in relation to host and disease characteristics. PLoS ONE. (2015) 10:E0127077. doi: 10.1371/journal.pone.0127077

76. Radaic A, Kapila YL. The oralome and its dysbiosis: new insights into oral microbiome-host interactions. Comput Struct Biotechnol J. (2021) 19:133560. doi: 10.1016/j.csbj.2021.02.010

77. Kuss SK, Best GT, Etheredge CA, Pruijssers AJ, Frierson JM, Hooper LV, et al. Intestinal microbiota promote enteric virus replication and systemic pathogenesis. Science. (2011) 334:249-52. doi: 10.1126/science.1211057

78. Erickson AK, Jesudhasan PR, Mayer MJ, Narbad A, Winter SE, Pfeiffer JK. Bacteria facilitate enteric virus co-infection of mammalian cells and promote genetic recombination. Cell Host Microbe. (2018) 23:7788.e5. doi: 10.1016/j.chom.2017.11.007

79. Slots J. Human viruses in periodontitis. Periodontol 2000. (2010). 53:89110. doi: 10.1111/j.1600-0757.2009.00325.x

80. Soffritti I, D’Accolti M, Fabbri C, Passaro A, Manfredini R, Zuliani G, et al. Oral microbiome dysbiosis is associated with symptoms severity and local immune/inflammatory response in COVID-19 patients: a cross-sectional study. Front Microbiol. (2021) 12:1397. doi: 10.3389/fmicb.2021.687513

81. Khassawneh B, Alhabashneh R, Ibrahim F. The association between bronchial asthma and periodontitis: a case-control study in Jordan. J Asthma. (2019) 56:404-10. doi: 10.1080/02770903.2018.1466315

82. Gomes-Filho IS, Cruz SSD, Trindade SC, Passos-Soares JS, CarvalhoFilho PC, Figueiredo A, et al. Periodontitis and respiratory diseases: a systematic review with meta-analysis. Oral Dis. (2020) 26:439-46. doi: 10.1111/odi.13228

83. Hobbins S, Chapple IL, Sapey E, Stockley RA. Is periodontitis a comorbidity of COPD or can associations be explained by shared risk factors/behaviors? Int J Chron Obstruct Pulmon Dis. (2017) 12:133949. doi: 10.2147/COPD.S127802

84. Mehta P, McAuley DF, Brown M, Sanchez E, Tattersall RS, Manson JJ. COVID-19: consider cytokine storm syndromes and immunosuppression. Lancet. (2020) 395:1033-4. doi: 10.1016/S0140-6736(20)30628-0

85. Hu B, Huang S, Yin L. The cytokine storm and COVID-19. J Med Virol. (2021) 93:250-6. doi: 10.1002/jmv.26232

86. Xu Z, Shi L, Wang Y, Zhang J, Huang L, Zhang C, et al. Pathological findings of COVID-19 associated with acute respiratory distress syndrome. Lancet Respir Med. (2020) 8:420-2. doi: 10.1016/S2213-2600(20)30076-X

87. Hayney MS, Henriquez KM, Barnet JH, Ewers T, Champion HM, Flannery $\mathrm{S}$, et al. Serum IFN- $\Gamma$-Induced protein 10 (IP-10) as a biomarker for severity of acute respiratory infection in healthy adults. J Clin Virol. (2017) 90:32-7. doi: 10.1016/j.jcv.2017.03.003

88. Pum A, Ennemoser M, Adage T, Kungl AJ. Cytokines and chemokines in SARS-CoV-2 infections-therapeutic strategies targeting cytokine storm. Biomolecules. (2021) 11:91. doi: 10.3390/biom11010091

89. Chong WP, Ip WK, Tso GH, Ng MW, Wong WH, Law HK, et al. The interferon gamma gene polymorphism $+874 \mathrm{~A} / \mathrm{T}$ is associated with severe acute respiratory syndrome. BMC Infect Dis. (2006) 6:82. doi: 10.1186/1471-2334-6-82

90. Tynell J, Westenius V, Rönkkö E, Munster VJ, Melén K, Österlund P, et al. Middle east respiratory syndrome coronavirus shows poor replication but significant induction of antiviral responses in human monocytederived macrophages and dendritic cells. J Gen Virol. (2016) 97:34455. doi: 10.1099/jgv.0.000351

91. Acharya AB, Thakur S, Muddapur MV, Kulkarni RD. Cytokine ratios in chronic periodontitis and type 2 diabetes mellitus. Diabetes Metab Syndr. (2017) 11:277-8. doi: 10.1016/j.dsx.2016.12.007

92. Chapple ILC, Genco R, Workshop WgotjEA. Diabetes and periodontal diseases: consensus report of the joint EFP/AAP workshop on periodontitis and systemic diseases. J Clin Periodontol. (2013) 40:S106-S12. doi: $10.1111 /$ jcpe. 12077

93. Hajishengallis G, Korostoff JM. Revisiting the page \& schroeder model: the good, the bad and the unknowns in the periodontal host response 40 years later. Periodontol 2000. (2017) 75:116-51. doi: 10.1111/prd.12181

94. Stadler AF, Angst PD, Arce RM, Gomes SC, Oppermann RV, Susin C. Gingival crevicular fluid levels of cytokines/chemokines in chronic periodontitis: a meta-analysis. J Clin Periodontol. (2016) 43:727-45. doi: 10.1111/jcpe.12557

95. Herold T, Jurinovic V, Arnreich C, Lipworth BJ, Hellmuth JC, von BergweltBaildon M, et al. Elevated levels of IL-6 and CRP predict the need for mechanical ventilation in COVID-19. J Allergy Clin Immunol. (2020) 146:128-36.e4. doi: 10.1016/j.jaci.2020.05.008

96. Adriaensen W, Matheï C, Vaes B, van Pottelbergh G, Wallemacq $\mathrm{P}$, Degryse JM. Interleukin-6 as a first-rated serum inflammatory marker to predict mortality and hospitalization in the oldest old: a regression and CART approach in the BELFRAIL Study. Exp Gerontol. (2015) 69:53-61. doi: 10.1016/j.exger.2015.0 6.005

97. Yamaguchi T, Naruishi K, Arai H, Nishimura F, Takashiba S. IL-6/sIL-6R enhances cathepsin B and L production via Caveolin-1-mediated JNK-AP1 pathway in human gingival fibroblasts. J Cell Physiol. (2008) 217:42332. doi: $10.1002 /$ jcp. 21517

98. Takahashi Y, Watanabe N, Kamio N, Kobayashi R, Iinuma T, Imai K. Aspiration of periodontopathic bacteria due to poor oral hygiene potentially contributes to the aggravation of COVID-19. J Oral Sci. (2020) doi: 10.2334/josnusd.20-0388

99. Faure E, Poissy J, Goffard A, Fournier C, Kipnis E, Titecat M, et al. Distinct immune response in two MERS-CoV-Infected patients: can we go from bench to bedside? PLoS ONE. (2014) 9:E88716. doi: 10.1371/journal.pone.0088716

100. Josset L, Menachery VD, Gralinski LE, Agnihothram S, Sova P, Carter VS, et al. Cell host response to infection with novel human coronavirus 
EMC predicts potential antivirals and important differences with SARS coronavirus. MBio. (2013) 4:E00165-13. doi: 10.1128/mBio.00165-13

101. Bermejo-Martin JF, Ortiz de Lejarazu R, Pumarola T, Rello J, Almansa R, Ramírez P, et al. Th1 and Th17 hypercytokinemia as early host response signature in severe pandemic influenza. Crit Care. (2009) 13:R201. doi: $10.1186 / \mathrm{cc} 8208$

102. Cardoso CR, Garlet GP, Crippa GE, Rosa AL, Júnior WM, Rossi MA, et al. Evidence of the presence of $\mathrm{T}$ helper type 17 cells in chronic lesions of human periodontal disease. Oral Microbiol Immunol. (2009) 24:16. doi: 10.1111/j.1399-302X.2008.00463.x

103. Adibrad M, Deyhimi P, Ganjalikhani Hakemi M, Behfarnia P, Shahabuei M, Rafiee L. Signs of the presence of Th17 cells in chronic periodontal disease. $J$ Periodontal Res. (2012) 47:525-31. doi: 10.1111/j.1600-0765.2011.01464.x

104. Graves D. Cytokines that promote periodontal tissue destruction. $J$ Periodontol. (2008) 79(8 Suppl):1585-91. doi: 10.1902/jop.2008.080183

105. Ruddy MJ, Shen F, Smith JB, Sharma A, Gaffen SL. Interleukin-17 regulates expression of the CXC chemokine LIX/CXCL5 in osteoblasts: implications for inflammation and neutrophil recruitment. J Leukoc Biol. (2004) 76:13544. doi: $10.1189 / \mathrm{jlb} .0204065$

106. Allam JP, Duan Y, Heinemann F, Winter J, Götz W, Deschner J, et al. IL23-producing CD68(+) macrophage-like cells predominate within an IL-17polarized infiltrate in chronic periodontitis lesions. J Clin Periodontol. (2011) 38:879-86. doi: 10.1111/j.1600-051X.2011.01752.x

107. White PC, Chicca IJ, Cooper PR, Milward MR, Chapple IL. Neutrophil extracellular traps in periodontitis: a web of intrigue. J Dent Res. (2016) 95:26-34. doi: 10.1177/0022034515609097

108. Schönrich G, Raftery MJ. Neutrophil extracellular traps go viral. Front Immunol. (2016) 7:366. doi: 10.3389/fimmu.2016.00366

109. Wong JJM, Leong JY, Lee JH, Albani S, Yeo JG. Insights into the immunopathogenesis of acute respiratory distress syndrome. Ann Transl Med. (2019) 7:4. doi: 10.21037/atm.2019.09.28

110. Grabcanovic-Musija F, Obermayer A, Stoiber W, Krautgartner WD, Steinbacher P, Winterberg N, et al. Neutrophil extracellular trap (NET) formation characterises stable and exacerbated COPD and correlates with airflow limitation. Respir Res. (2015) 16:59. doi: 10.1186/s12931-015-0221-7

111. Brill A, Fuchs TA, Savchenko AS, Thomas GM, Martinod K, De Meyer SF, et al. Neutrophil extracellular traps promote deep vein thrombosis in mice. $J$ Thromb Haemost. (2012) 10:136-44. doi: 10.1111/j.1538-7836.2011.04544.x

112. Fuchs TA, Brill A, Duerschmied D, Schatzberg D, Monestier M, Myers DD, et al. Extracellular DNA traps promote thrombosis. Proc Natl Acad Sci U S A. (2010) 107:15880-5. doi: 10.1073/pnas.1005743107

113. Klok FA, Kruip M, van der Meer NJM, Arbous MS, Gommers $\mathrm{D}$, Kant $\mathrm{KM}$, et al. Incidence of thrombotic complications in critically ill ICU patients with COVID-19. Thromb Res. (2020) 191:145-7. doi: 10.1016/j.thromres.2020.04.013

114. de Oliveira FL, Gatto M, Bassi N, Luisetto R, Ghirardello A, Punzi L, et al. Galectin-3 in autoimmunity and autoimmune diseases. Exp Biol Med. (2015) 240:1019-28. doi: 10.1177/1535370215593826

115. Caniglia JL, Guda MR, Asuthkar S, Tsung AJ, Velpula KK. A potential role for galectin-3 inhibitors in the treatment of COVID-19. PeerJ. (2020) 8:E9392. doi: 10.7717/peerj.9392

116. Chen SS, Sun LW, Brickner H, Sun PQ. Downregulating galectin3 inhibits proinflammatory cytokine production by human monocytederived dendritic cells via RNA interference. Cell Immunol. (2015) 294:4453. doi: 10.1016/j.cellimm.2015.01.017

117. Ogawa Y, Kanai-Azuma M, Akimoto Y, Kawakami H, Yanoshita R. Exosomelike vesicles with dipeptidyl peptidase IV in human saliva. Biol Pharm Bull. (2008) 31:1059-62. doi: 10.1248/bpb.31.1059

118. Krishnamoorthy N, Abdulnour RE, Walker KH, Engstrom BD, Levy BD. Specialized proresolving mediators in innate and adaptive immune responses in airway diseases. Physiol Rev. (2018) 98:1335-70. doi: 10.1152/physrev.00026.2017

119. Serhan CN, Chiang N, Dalli J. New pro-resolving n-3 mediators bridge resolution of infectious inflammation to tissue regeneration. Mol Aspects Med. (2018) 64:1-17. doi: 10.1016/j.mam.2017.08.002

120. Serhan CN, Jain A, Marleau S, Clish C, Kantarci A, Behbehani $\mathrm{B}$, et al. Reduced inflammation and tissue damage in transgenic rabbits overexpressing 15-lipoxygenase and endogenous antiinflammatory lipid mediators. J Immunol. (2003) 171:685665. doi: 10.4049/jimmunol.171.12.6856

121. Osorio Parra MM, Elangovan S, Lee CT. Specialized pro-resolving lipid mediators in experimental periodontitis: a systematic review. Oral Dis. (2019) 25:1265-76. doi: 10.1111/odi.12979

122. Siddiqui YD, Omori K, Ito T, Yamashiro K, Nakamura S, Okamoto K, et al. Resolvin D2 induces resolution of periapical inflammation and promotes healing of periapical lesions in rat periapical periodontitis. Front Immunol. (2019) 10:307. doi: 10.3389/fimmu.2019.00307

123. Montero E, Lopez M, Vidal H, Martinez M, Virto L, Marrero J, et al. Impact of periodontal therapy on systemic markers of inflammation in patients with metabolic syndrome: a randomized clinical trial. Diabetes Obes Metab. (2020) 22:2120-32. doi: 10.21203/rs.3.rs-25563/v1

124. D'Aiuto F, Orlandi M, Gunsolley JC. Evidence that periodontal treatment improves biomarkers and CVD outcomes. J Clin Periodontol. (2013) 40 Suppl 14:S85-105. doi: 10.1111/jcpe.12061

125. Katagiri $S$, Nitta $H$, Nagasawa $T$, Uchimura I, Izumiyama $H$, Inagaki $K$, et al. Multi-center intervention study on glycohemoglobin (HbAlc) and serum, high-sensitivity crp (hs-CRP) after local anti-infectious periodontal treatment in type 2 diabetic patients with periodontal disease. Diabetes Res Clin Pract. (2009) 83:308-15. doi: 10.1016/j.diabres.2008.10.016

126. Shimada Y, Komatsu Y, Ikezawa-Suzuki I, Tai H, Sugita N, Yoshie H. The effect of periodontal treatment on serum leptin, interleukin-6, and C-reactive protein. J Periodontol. (2010) 81:1118-23. doi: 10.1902/jop.2010.090741

127. Simpson TC, Weldon JC, Worthington HV, Needleman I, Wild SH, Moles DR, et al. Treatment of periodontal disease for glycaemic control in people with diabetes mellitus. Cochrane Database Syst Rev. (2015) 2015:Cd004714. doi: 10.1002/14651858.CD004714.pub3

128. Abe S, Ishihara K, Adachi M, Sasaki H, Tanaka K, Okuda K. Professional oral care reduces influenza infection in elderly. Arch Gerontol Geriatr. (2006) 43:157-64. doi: 10.1016/j.archger.2005.10.004

129. Chambrone L, Foz AM, Guglielmetti MR, Pannuti CM, Artese HP, Feres $\mathrm{M}$, et al. Periodontitis and chronic kidney disease: a systematic review of the association of diseases and the effect of periodontal treatment on estimated glomerular filtration rate. J Clin Periodontol. (2013) 40:44356. doi: 10.1111 /jcpe. 12067

130. Teeuw WJ, Slot DE, Susanto H, Gerdes VE, Abbas F, D'Aiuto F, et al. Treatment of periodontitis improves the atherosclerotic profile: a systematic review and meta-analysis. J Clin Periodontol. (2014) 41:709. doi: $10.1111 /$ jcpe. 12171

131. Tonetti MS, Van Dyke TE. Periodontitis and atherosclerotic cardiovascular disease: consensus report of the joint EFP/AAPWorkshop on periodontitis and systemic diseases. Journal of Periodontology. (2013) 84:S24-S9. doi: 10.1902/jop.2013.1340019

132. Cordon-Cardo C, Pujadas E, Wajnberg A, Sebra R, Patel G, Firpo-Betancourt A, et al. COVID-19: staging of a new disease. Cancer Cell. (2020) 38:5947. doi: $10.1016 /$ j.ccell.2020.10.006

Conflict of Interest: The authors declare that the research was conducted in the absence of any commercial or financial relationships that could be construed as a potential conflict of interest.

Publisher's Note: All claims expressed in this article are solely those of the authors and do not necessarily represent those of their affiliated organizations, or those of the publisher, the editors and the reviewers. Any product that may be evaluated in this article, or claim that may be made by its manufacturer, is not guaranteed or endorsed by the publisher.

Copyright (c) 2021 Cai, Marouf, Said and Tamimi. This is an open-access article distributed under the terms of the Creative Commons Attribution License (CC BY). The use, distribution or reproduction in other forums is permitted, provided the original author(s) and the copyright owner(s) are credited and that the original publication in this journal is cited, in accordance with accepted academic practice. No use, distribution or reproduction is permitted which does not comply with these terms. 